\title{
Pre and post orthodontic treatment changes in the sagittal and vertical skeletal dimension following all four first premolar extractions.
}

\footnotetext{
1. BDS, FCPS

Assistant Professor (Orthodontics) JMDC.

2. BDS, FCPS, M-Orth

Professor (Orthodontics)

DIEKIOHS, DUHS.

3. BDS, FCPS

Assistant Professor (Orthodontics) JSMU.

4. BDS, FCPS

Assistant Professor (Orthodontics) DIEKIOHS, DUHS.
}

\section{Correspondence Address:}

Dr. Hana Pervez

Department of Orthodontics

JMDC

drhanapervez@gmail.com

Article received on:

30/03/2020

Accepted for publication:

02/06/2020
Hana Pervez ${ }^{1}$, Imtiaz Ahmed², Erum Behroz ${ }^{3}$, Sadia Rizwan ${ }^{4}$

ABSTRACT... Objectives: To determine mean change in sagittal and vertical skeletal dimension in patients undergoing orthodontic treatment with all four first premolar extractions. Study Design: Quasi-experimental study design. Setting: Department of Orthodontics, Dr. Ishrat-Ul-Ebad Khan Institute of Oral Health Sciences, Dow University of Health Sciences, Karachi. Period: Six months from $18^{\text {th }}$ August 2015 to $18^{\text {th }}$ February 2016. Material \& Methods: 50 cases treated with all first premolar extractions were included in this study. The analysis was done on pretreatment cephalogram taken at time of enrolment and post treatment lateral cephalogram taken after 12 months of orthodontic treatment and then their measurements were compared to find out changes in the sagittal and vertical dimension. Results: Pre and post mean SNA, SNB, ANB and Pog-Nperp was not significant while mean A-Nperp was significantly changed after 12 month treatment $(p=0.002)$. Regarding angular measurement, pre and post mean SNMP, FHMP, MMA, Go-OP, SN-OP, Y axis was not significant while mean SN-PP, UI_SN, IMPA was significantly reduced after 12 month treatment. Similarly vertical measurement, pre and post mean LAFH, PFH was not significant while mean UAFH and, TAFH was significantly reduced after 12 months of treatment. Conclusion: Sagittal and vertical skeletal dimension showed no significant change in patients undergoing orthodontic treatment with all four first premolar extractions. Some degree of extrusion was noted in all orthodontic patients who have undergone all four first premolar extractions.

Key words: Cephalogram, Crowding, Facial Profile.

Article Citation: Pervez H, Ahmed I, Behroz E, Rizwan S. Pre and post orthodontic treatment changes in the sagittal and vertical skeletal dimension following all four first premolar extractions. Professional Med J 2020; 27(12):2775-2779. https://doi.org/10.29309/TPMJ/2020.27.12.4688

\section{INTRODUCTION}

For the alleviation of dental crowding, extraction of tooth is a commonly performed procedure and its frequency among orthodontic patients has been reported to be 42.1 percent. $^{1}$

There have been a lot of controversies regarding extraction and non-extraction approaches in orthodontics. Angle was in favour of nonextraction treatment modality however Sassouni and $\mathrm{Nanda}^{2}$ are in favour of extraction approach when necessary. Sassouni was one of the first investigators to bring attention to the vertical dimension in orthodontic diagnosis. ${ }^{2}$

According to Schudy, facial types are categorized as hyperdivergent and hypodivergent. $\mathrm{He}$ suggested extraction approach in high angle cases while non-extraction approach in low angle cases. He was of the view that extraction in high angle cases will result in closing down of bite reducing the hyperdivergence of face. ${ }^{3}$

Most commonly extracted teeth for orthodontic purpose are premolars. ${ }^{4}$ Extraction of premolars is a common practice, however, its effects on vertical facial dimension and temporomandibular disorders is still a matter of great debate. ${ }^{5}$ The hypothesis suggesting the result of premolar extraction on facial dimension vertically is highly disapproved by various data and reports. ${ }^{6,7}$

Several authors have recommended that removing of permanent teeth from posterior buccal segment followed by mesialization to close extraction space favours closing of bite by 
downward and backward rotation of mandible. As first premolar extraction is indicated in cases with crowding and lip procumbency ${ }^{8}$, most of the space is utilized for the alleviation of crowding. The space left after the relief of crowding is used up by the reciprocal movement of molars and incisor. So the amount of mesial molar movement will be negligible in cases with all four first permanent molars. ${ }^{9}$ Theoretically, the more distance molars move forward, the more obvious the counterclockwise rotation would appear. This rationale for extraction is referred to as 'wedge hypothesis. ${ }^{10}$

Effect of bicuspid extraction on vertical skeletal plane is still a matter of debate. It has been suggested by various authors that protraction of posterior teeth after premolar extraction results in reduction in vertical plane and over closure of musculature. ${ }^{11}$

The objective of the study is to determine mean change in sagittal and vertical skeletal dimension in patients undergoing orthodontic treatment with all four first premolar extractions.

\section{MATERIAL \& METHODS}

Fifty cases treated with all first premolar extractions were included in this study. The case selection was done on the basis of need of extractions of all four first premolars in order to relieve crowding or anterior teeth proclination issues.

The approval of the study was taken from CPSP (College of physician and surgeon), Karachi. The written informed consent was taken from the patients whose cephalometric radiographs were used for this study. The analysis was done on pretreatment cephalogram taken at time of enrolment and post treatment lateral cephalogram taken after 12 months of orthodontic treatment and then their measurements were compared to find out changes in the sagittal and vertical dimension.

\section{Cephalometric Recording}

Single techinician took lateral cephalogram with the same $x$-ray machine in order to maintain standardization. The cephalograms were made with the mandible in the centric occlusion position. The distance between the film and midsagittal plane for lateral cephalostat was fixed at $15 \mathrm{~cm}$. While taking the cephalogram, it was made sure that Frankfort horizontal plane should be parallel to the floor. Following angular and linear measurements were used to evaluate vertical and sagittal dimensional changes.

Angular Cephalometric Measurements SNMP: Angle between the Sella Nasion (S-Na) plane and mandibular plane i.e Gonion Menton plane (Go-Me).

FHMP It is the angular measurement between Frankfort horizontal plane and mandibular plane.

MMA: It is the angular measurement between mandibular plane and palatal plane.

Go-OP: It is the angular measurement between mandibular plane and occlusal plane.

SN-PP: It is the angular measurement between Sella Nasion SN-palatal plane.

SN-OP: It is the angular measurement between Sella Nasion and occlusal plane.

UI-SN: It is the angle formed by long axis of maxillary central incisor with the sella nasion plane.

IMPA: It is the angle formed by the long axis of mandibular incisor with the mandibular plane.

Y-axis: It is the angle formed by Frankfort horizontal plane and sella gnathion

Vertical Measurements

UAFH ( upper anterior face height) It is the linear distance from Nasion to ANS.

TAFH ( total anterior face height)It is the linear distance from Nasion to Menton.

LAFH ( lower anterior face height)It is the linear distance from ANS to Menton. 
PFH ( posterior face height)lt is the linear distance from Sella to Gonion

\section{Data Analysis}

- Statistical package for the social sciences (SPSS for windows version 16) was used for the statistical analysis.

- The mean and standard deviations was calculated to analyze post treatment vertical changes cephalometrically. P-value of 0.05 or less will be considered for statistical significance

\section{RESULTS}

Mean change in sagittal skeletal dimension in patients undergoing orthodontic treatment with all four first premolar extractions is shown in Table-I. Pre and post mean SNA, SNB, ANB and Pog-Nperp was not significant while mean A-Nperp was significantly changed after 12 month treatment $(p=0.002)$.
Mean change in vertical skeletal dimension in patients undergoing orthodontic treatment with all four first premolar extractions is shown in table II. Regarding angular measurement, pre and post mean SNMP, FHMP, MMA, Go-OP, SN-OP, Y axis was not significant while mean SN-PP, UI_SN, IMPA was significantly reduced after 12 month treatment. Similarly vertical measurement, pre and post mean LAFH, PFH was not significant while mean UAFH and, TAFH was significantly reduced after 12 months treatment as shown in Table-Il.

\section{DISCUSSION}

Stable orthodontic treatment outcome is considered to be an uphill task for all orthodontists. ${ }^{12}$ Even if extractions are done for the relief of crowding, stability after orthodontic therapy is still highly questionable.

\begin{tabular}{|c|c|c|c|c|}
\hline $\begin{array}{l}\text { SAGITTAL } \\
\text { Variables }\end{array}$ & $\begin{array}{c}\text { Pretreatment } \\
\text { (at time of enrolment) } \\
\text { Mean } \pm \text { S.D }\end{array}$ & $\begin{array}{c}\text { Post treatment (after } 12 \\
\text { months of treatment } \\
\text { Mean } \pm \text { S.D }\end{array}$ & $\begin{array}{l}\text { Mean change } \\
\text { Mean } \pm S . D\end{array}$ & P-Value \\
\hline SNB & $79.63 \pm 4.06$ & $79.63 \pm 3.99$ & $00 \pm 0.50$ & 0.99 \\
\hline ANB & $1.82 \pm 1.01$ & $1.94 \pm 1.05$ & $0.12 \pm 0.72$ & 0.24 \\
\hline Pog -Nperp & $2.78 \pm 1.02$ & $2.94 \pm 1.16$ & $0.16 \pm 0.92$ & 0.22 \\
\hline
\end{tabular}

\begin{tabular}{|c|c|c|c|c|}
\hline Vertical & $\begin{array}{c}\text { Pretreatment } \\
\text { (at time of enrolment) } \\
\text { Mean } \pm \text { S.D }\end{array}$ & $\begin{array}{c}\text { Post treatment (after } 12 \\
\text { months of treatment } \\
\text { Mean } \pm \text { S.D }\end{array}$ & $\begin{array}{c}\text { Mean change } \\
\text { Mean } \pm S . D\end{array}$ & P-Value \\
\hline SNMP & $34.33 \pm 4.89$ & $34.18 \pm 4.89$ & $0.14 \pm 1.45$ & 0.49 \\
\hline FHMP & $26.63 \pm 18.12$ & $26.41 \pm 4.67$ & $0.22 \pm 2.07$ & 0.45 \\
\hline Go-OP & $18.49 \pm 16.07$ & $20.65 \pm 17.82$ & $2.13 \pm 13.06$ & 0.25 \\
\hline SN-PP & $7.31 \pm 3.26$ & $7.08 \pm 3.22$ & $0.22 \pm 0.58$ & $0.01 *$ \\
\hline SN-OP & $6.43 \pm 2.23$ & $6.29 \pm 2.16$ & $0.14 \pm 0.76$ & 0.19 \\
\hline UI_SN & $109.96 \pm 8.95$ & $101.96 \pm 5.04$ & $7.71 \pm 8.12$ & $0.005^{\star}$ \\
\hline
\end{tabular}

Table-II. Mean change in vertical skeletal dimension in patients undergoing orthodontic treatment with all four first premolar extractions 
Therefore the topic of whether treating an orthodontic case with extraction or non-extraction is considered to be a bone of contention. ${ }^{13,14}$ The tooth which is routinely extracted for orthodontic reasons are premolars. ${ }^{14}$ Basic reasons for the extraction of this tooth is to alleviate crowding and to correct bimaxillary proclinations. The location of premolars is considered to be ideal both for the resolution of crowding and for the correction of inclinations. ${ }^{15}$ Several authors have recommended that removing permanent teeth from posterior buccal segment followed by mesialization to close extraction space favours closing of bite by downward and backward rotation of mandible. As first premolar extraction is indicated in cases with crowding and lip procumbency ${ }^{11}$, most of the space is utilized for the alleviation of crowding. The space left after the relief of crowding is used up by the reciprocal movement of molars and incisor. So the amount of mesial molar movement will be negligible in cases with all four first permanent molars. ${ }^{16}$ Theoretically, the more distance molars move forward, the more obvious the counterclockwise rotation would appear. This rationale for extraction is referred to as 'wedge hypothesis. ${ }^{17}$

In this study pre and post mean SNA, SNB, ANB and Pog-Nperp was not significant while mean A-Nperp was significantly change after 12 month treatment $(p=0.002)$. Effect of bicuspid extraction on vertical skeletal plane is still a matter of debate. It has been suggested by various authors that protraction of posterior teeth after premolar extraction results in reduction in vertical plane and over closure of musculature. ${ }^{11}$ In one study conducted by MeenaKumari ${ }^{11}$, facial height (total anterior face height) was increased following all four first premolar extraction with pretreatment mean of 117.7 (S.D \pm 6.45$)$ and post treatment mean of 119.2 (S.D \pm 7.0 ). The mean difference was $1.5 \pm 0.55$ with $p$-value of (0.005).

No major arch dimensional changes is reported with the orthodontic treatment. ${ }^{18,19}$ In this study, regarding angular measurement, pre and post mean SNMP, FHMP, MMA, Go-OP, SN-OP, Y axis was not significant while mean SN-PP, UI_SN, IMPA was significantly reduced after 12 month treatment. Similarly vertical measurement, pre and post mean LAFH, PFH was not significant while mean UAFH and, TAFH was significantly reduced after 12 months treatment.

Some studies supported the fact that with the extraction of tooth, face height decreases or it has a bite deepening effect. ${ }^{15}$ It was reported that protraction of molars leads to alveolar bone collapse especially in mandible resulting in decrease in face height. Some studies are not in favor of this hypothesis. ${ }^{16}$ According to Chua et al. ${ }^{16}$, no major change was reported in face height with the extractions; later on several studies on the other hand concluded that there is an increase in vertical height with the extraction modality. ${ }^{17,18}$

If orthodontic treatment is completed before growth, then clinician must anticipate future changes that can take place due to growth once orthodontic appliances have been removed. Extraction or non-extraction treatment plans are basically designed to fulfill the needs of patients. Major aim is to achieve desired goals which are aesthetics, function and stability. If any of the goals is compromised, treatment outcome will not be acceptable

\section{CONCLUSION}

Sagittal and vertical skeletal dimension showed no significant change in patients undergoing orthodontic treatment with all four first premolar extractions. Some degree of extrusion was noted in all orthodontic patients who have undergone all four first premolar extractions.

Copyright $(02$ June, 2020.

\section{REFERENCES}

1. Al-Nimri KS. Vertical changes in class II division 1 malocclusion after premolar extractions. Angle Orthod. 2006; 76:52-8.

2. Scott Conley R, Jernigan C. Soft tissue changes after upper premolar extraction in Class II camouflage therapy. Angle Orthod. 2006; 76(1):59-65.

3. Hans MG, Groisser G, Damon C, Amberman D, Nelson $\mathrm{S}$, Palomo JM. Cephalometric changes in overbite and vertical facial height after removal of 4 first molars or first premolars. Am J Orthod Dentofacial Orthop. 2006; 130:183-8. 
4. Khan $M$, Fida $M$. Soft tissue profile response in extraction versus non-extraction orthodontic treatment. J Coll Physicians Surg Pak. 2010 Jul; 20(7):454.

5. Al-Nimri KS. Vertical changes in class II division 1 malocclusion after premolar extractions. Angle Orthod. 2006; 76:52-8.

6. Daokar ST, Rajput R: Cephalometric appraisal of antero-posterior skeletal discrepancy: An overview. Orthodontic journal of Nepal, 2018; 25; 15(1):44.

7. Jin-le Li, Chung How Kau and Min Wang. Changes of occlusal plane inclination after orthodontic treatment in different dentoskeletal frames. Prog Orthod. 2014; 25;15(1):41.

8. Rosati R, Rossetti A, Menezes MD, Ferrario VF, Sforza $C$. The occlusal plane in the facial context: Interoperator repeatability of a new three-dimensional method. Int J Oral Sci. 2012; 4:34-7.

9. Kattadiyil MT, Goodacre CJ, Naylor WP, Maveli TC. Esthetic smile preferences and the orientation of the maxillary occlusal plane. J Prosthet Dent. 2012; 108:354-61.

10. Kumari M, Fida M. Vertical facial and dental arch dimensional changes in extraction versus nonextraction orthodontic treatment. J Coll Physicians Surg Pak. 2010; 20:17-21.

11. Hayasaki SM, Castanha Henriques JF, Janson G, de Freitas MR. Influence of extraction and non-extraction orthodontic treatment in Japanese-Brazilians with class I and class II division 1 malocclusions. Am J Orthod Dentofacial Orthop. 2005; 127:30-6.
12. Ahmed M, Shaikh A, Fida M. Diagnostic performance of various cephalometric parameters for the assessment of vertical growth pattern. Dental Press J Orthod. 2016 Aug; 21(4):41-9.

13. Hans MG, Groisser G, Damon C, Amberman D, Nelson $\mathrm{S}$, Palomo JM. Cephalometric changes in overbite and vertical facial height after removal of 4 first molars or first premolars. Am J Orthod Dentofacial Orthop 2006; 130:183-8.

14. Bhad WA, Subash N, Umal HD. A new approach of assessing sagittal dysplasia: The W Angle. Eur J Orthod. 2013 Feb; 35(1):66-70.

15. G. Perinetti, J. Primožič, G. Furlani, L. Franchi, and L. Contardo, "Treatment effects of fixed functional appliances alone or in combination with multibracket appliances: A systematic review and meta-analysis," The Angle Orthodontist, 2015; 85(5); 480-492.

16. Janson G, Laranjeira V, Rizzo M, Garib D. Posterior tooth angulations in patients with anterior open bite and normal occlusion. Am J Orthod Dentofacial Orthop. 2016 July; 150(1):71-7.

17. Sivakumar A, Valiathan A. Cephalometric assessment dentofacial vertical changes in Class I subjects treated with and without extraction. Am J Orthod Dentofacial Orthop 2008; 133: 869-75.

18. Khan $M$, Fida $M$. Soft tissue profile response in extraction versus non-extraction orthodontic treatment. J Coll Physicians Surg Pak. 2010 Jul; 20(7):454-9.

\begin{tabular}{|c|l|l|l|}
\hline \multicolumn{3}{|c|}{ AUTHORSHIP AND CONTRIBUTION DECLARATION } \\
\hline Sr. \# & \multicolumn{1}{|c|}{ Author(s) Full Name } & Contribution to the paper & Author(s) Signature \\
\hline 1 & Hana Pervez & Article writing, Data analysis. \\
\hline 2 & Imtiaz Ahmed & Data collection. \\
\hline 3 & Erum Behroz & Data collection. & \\
\hline 4 & Sadia Rizwan & Data analysis. & \\
\hline
\end{tabular}

